\title{
personal account
}
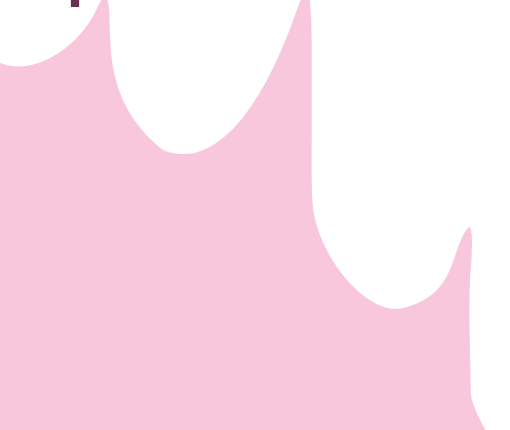

Your chairside
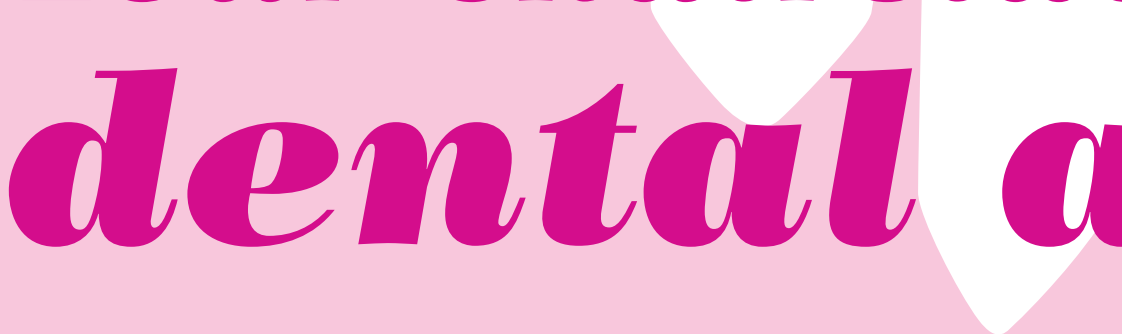

\section{Dental nurse Claire Thorburn shares her experiences lecturing in four-handed dentistry.}

I started lecturing in four-handed dentistry courses for vocational dental practitioners (VDPs) with my boss and two dental nurse colleagues a few years ago. We had the lectures down a fine art with Martyn, the dentist, taking the lead and Sally, Emma and me putting our own input into what is a very enjoyable, informative and practical day on how to make the most of your nurse. So, when we were approached to do a four-handed dentistry lecture without Martyn, who couldn't attend, it was very daunting! Could we pull off a full day's lecture with 12-14 VDPs and their nurses without a dentist present?

Sally, Emma and I put our heads together to plan how to execute a lecture with no dentist present as a 'symbol' of expertise and knowledge. We have been implementing four-handed dentistry in our practice for over 30 years, so we could speak from experience. We were of course very familiar with the fourhanded dentistry course structure, but this was a new challenge, and one which we were determined to take on. As a profession dental nurses are constantly striving to be appreciated and acknowledged.

\section{Planning}

We started by thinking of a way to win the VDPs' trust in us. To begin with we would introduce ourselves and our roles within our daily working lives. We got to work preparing a slide show arrangement, including slides of our practice and a summary of what the course that day would be about and what they could expect from us. We devised games and teambuilding exercises to put the VDPs at ease and prepared the instrument bags for the practical sessions. We discussed between us how we wanted the day to go and who would speak at which point during the slide show, to ensure it would all run smoothly.

\section{'As a nurse you should adjust} the dental chair so that you have
better vision, rather than

\section{trying to crane your neck.'}

\section{On location}

The day approached and we were quite nervous as we arrived at the A-Dec centre in Nuneaton early to set up. The nerves were starting to

\section{mey}

in and

we were

desperate for

the lecture to be

a success, not only for

the VDPs and their nurses

but for ourselves and Martyn.

He has been lecturing successfully

on four-handed dentistry for the past

18 years, so his reputation was at stake.

VDPs have just embarked on their careers in dentistry, so the course objective was to help them make the most of their nurses so that they can establish and maintain a balanced, fulfilling work environment.

There were 24 people in total, which doesn't sound that many, but our job was to keep them all interested for six hours and for them to leave with the motivation to implement our ideas and handy tips into practical working life. We explained that the day would include communication skills, surgery layout and practical four-handed dentistry.

\section{Working as a team}

Our preparation started to pay off as the day progressed. The communication and team building games got everyone talking and really put them at ease. For example, we got everyone to pair up and stand back to back; one person had to describe an object without 
The rest of the afternoon was made up of the practical four-handed techniques with the dentists and nurses practising all the things they had learnt: correct posture, seating arrangements, cross infection control using safe instrument exchange and soft

the tray

of instruments

in an orderly fashion and ensure safe instrument exchange while treatment is in progress. We all know how messy dentists can be sometimes, and picking up a dirty tray at the end of a session isn't very appealing.

\section{Ergonomics}

using

words that would give it away, and the other person had to draw

it. This was an interesting exercise in communication, making the VDPs and their nurses realise that in order for the surgery to run efficiently, communication is paramount, and how easy it is for communication to break down.

Convincing the dentists to use their nurses to their full potential was achieved by suggesting to the nurses that they have all the instruments on their side of the dental chair, which ultimately allows four-handed dentistry to be carried out.

If you think about this for a moment it makes sense for the nurse to have all the instruments on her side, passing the instruments from the tray to the dentist, which allows the dentist to concentrate on the procedure in hand without having to look up.

With most dentists wearing loupes these days, their field of vision is limited; therefore being handed an instrument by the nurse is far easier than the dentist wasting time grappling for the right instrument. Having the instruments on the nurse's side also helps maintain cross infection control, and the nurse can
Close support dentistry also allows the nurse to sit closer to the patient and, with a good chair, to adopt the correct posture. I was surprised how many nurses don't actually have a chair to sit on all day, and with the dentist taking a 12 o'clock position at the chair the nurse is forced to duck and dive blindly in, which is obviously bad for the nurse's posture. Ideally the nurse's chair should be higher than the dentist's, allowing a good sightline, and the dentist's and nurse's knees should be side-by-side or interlocking. Remember, the patient spends a relatively short time in the chair so move your patient to what is comfortable for both of you.

If you are doing multiple cavities upper and lower, as a nurse you should adjust the dental chair so that you have better vision, rather than trying to crane your neck. The patient won't mind and you will find it much more comfortable. Think about the times you have been to the hairdressers and they move your head to a position that is comfortable for them to work; you don't make a fuss as you know it will only be for a short while.

\section{Practice makes perfect}

We also discussed surgery design and Emma took a small group at a time to talk about their own surgeries and how four-handed dentistry could be used. These proved to be tissue retraction including aspirating techniques. We felt that the whole day had been a great success and this was backed up by the positive feedback we were given by both the dentists and the nurses who attended. This made us very proud.

\section{'This was a new}

\section{challenge, and}

one which we were determined to take on.'

For me personally I feel that this experience has opened up a whole new avenue and I have discovered that there is more to dentistry than being in the surgery. I was also inspired to write this article. So come on dentists, make the most of the dental angel sat next to you!

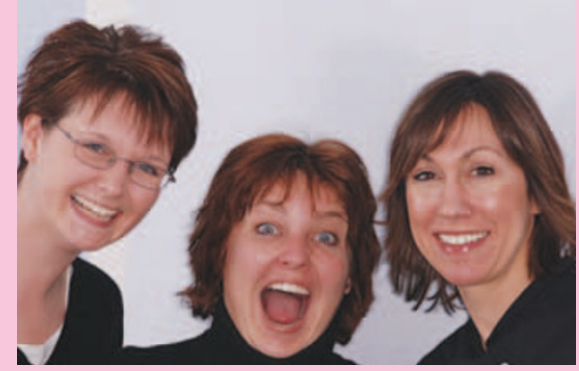

From left to right: Emma Harrison, Claire Thorburn and Sally Chadwick, all Registered Dental Nurses at Amsel and Wilkins Dental Surgery in Banbury. 